Article

\title{
The Advance Cancer Immunotherapy Techniques and the Fu- ture Perspective of Modified T Cell Therapy
}

\author{
Md. Al Saber', Partha Biswas ${ }^{2,3}$, Dipta Dey, ${ }^{4}$ Md. Abu Kaium², Md. Aminul Islam², Miss Ismoth Ara Tripty5 ${ }^{5}$ MD. \\ Hasanur Rahman 3, 6, Tanjim Ishraq Rahaman',6, Md. Yeaman Biswas², Priyanka Paul4, Md. Ataur Rahman ${ }^{7,8,9}$, Md. \\ Nazmul Hasan ${ }^{10 *}$, Bonglee $\mathrm{Kim}^{8}$ and ${ }^{9^{*}}$.
}

1 Biotechnology, University of Pécs, Medical School, Pécs-7624, Hungary.

2 Department of Genetic Engineering and Biotechnology, Faculty of Biological Science and Technology, Jashore University of Science and Technology (JUST), Jashore- 7408, Bangladesh.

3 ABEx Bio-Research Center, East Azampur, Dhaka 1230, Bangladesh.

4 Department of Biochemistry and Molecular Biology, Facility of Life Science, Bangabandhu Sheikh Mujibur Rahman Science and Technology University, Gopalgonj-8100, Bangladesh.

5 Agricultural Biotechnology, Hungarian University of Agriculture and Life Sciences (Former: Szent István University), Gödöllő-2100, Hungary.

6 Department of Biotechnology and Genetic Engineering, Bangabandhu Sheikh Mujibur Rahman Science and Technology University, Gopalganj 8100, Bangladesh.

7 Global Biotechnology \& Biomedical Research Network (GBBRN), Department of Biotechnology and Genetic Engineering, Faculty of Biological Sciences, Islamic University, Kushtia 7003, Bangladesh.

8 Department of Pathology, College of Korean Medicine, Kyung Hee University, Seoul 02447, South Korea.

9 Korean Medicine-Based Drug Repositioning Cancer Research Center, College of Korean Medicine, Kyung Hee University, Seoul 02447, Korea.

${ }_{10}$ Pharmaceutical Biotechnology Laboratory, Department of Genetic Engineering and Biotechnology, Faculty of Biological Science and Technology, Jashore University of Science and Technology (JUST), Jashore- 7408, Bangladesh.

* Correspondence: Md. Nazmul Hasan, Tel: +8801911-034367; Email: mnhasan1978@gmail.com Bonglee Kim, Phone: +82-2-961-9217; E-mail: bongleekim@khu.ac.kr

\begin{abstract}
The mechanisms involved in immune responses to cancer have been extensively studied for several decades and, considerable attention has been paid to harnessing the immune system's therapeutic potential. Cancer immunotherapy has established itself as a promising new treatment option for a variety of cancer types. Various strategies including cancer vaccines, monoclonal antibodies (mAbs), adoptive T-cell-cancer therapy and immune test therapy have gained prominence through immunotherapy. However, it remains to be accomplished the full potential of cancer immunotherapy. In spite of having startling aspects, the cancer immunotherapies have some difficulties including the inability to effectively targeting the cancer antigens and the abnormalities in patient response. With the advancement of technology, this system has changed the genome-based immunotherapy process in the human body including generation of engineered $\mathrm{T}$ cells. Due to its high specificity, CRISPR-Cas9 has become a simple and flexible genome-editing tool to target nearly any genomic locus. Recently, the CD19-mediated CAR-T cell (chimeric antigen receptor T cell) therapy has opened a new avenue for the treatment of human cancer, though low efficiency is a major drawback of this process. Thus, increasing the efficiency of the CAR-T cell (engineered T cells that induce the chimeric antigen receptor) by using CRISPR-Cas9 technology could be a better weapon to fight against the cancer. In this review, we have broadly focused on the use of CRISPR-Cas9 technology for the modification of the T-cell, which can specifically recognize cancer cells and be used as immune therapeutics against cancer. We have also demonstrated the other potential strategies for the treatment of cancer.
\end{abstract}

Keywords: Cancer Immunotherapy; Cancer Vaccine; Cancer Antigens; CRISPR-Cas9; Engineered T Cells 


\section{Introduction}

Cancer is the major increasing curse for human population throughout the world and second leading cause of death after the cardiovascular disease. So, the researchers are trying to ascertain the safe and efficient therapies for cancer treatment among them the 'immunotherapy' (i.e., enhance the immunity of body to fight against cancer) is the foremost therapeutic approaches [1]. Basically, it provides much potential and stable treatment strategy than other traditional cancer treatments. During the last decades, this cutting age approach has provided significant response against the cancer patient [2]. In immunotherapy techniques-T cell, NK cell, dendritic cells are directly involved to fight against the rapidly proliferating cells but they need modification for working effectively against cancer cells [3].

Tumor-Infiltrating Lymphocyte (TIL), Chimeric Antigen Receptor (CAR) T cell, Engineered Natural Killer cell (NK) therapy, Engineered T cell Receptor (TCR), Antibody therapy, immunomodulators, as well as CRISPR-Cas9 technique are common immunotherapy strategy among them modification of T cell and CRISPR-Cas9 is the most popular $[4,5]$. The future perspective of cancer treatment can be succeeded by the CAR-T (chimeric antigen receptor-T) cell immunotherapy, where the cells are actually generated by the modification of general T cells. Eventually, this modified T cells express pretended proteins recognized as CAR-T receptors which help the CAR- expressing immune cell to recognize the tumor antigens effectively [6]. In the recent time, many research activities have been demonstrated that B-cell lymphoma patients had shown decisive responses by using CAR-T cell therapies with using CD19-directed chimeric antigen receptor $\mathrm{T}$ cells (CART19). In USA, the FDA authorized two CD19-conducted genetically engineered autologous $\mathrm{T}$ cells named as Kymriah and Yescarta that applied in the patients who possessed the acute lymphoblastic leukemia (ALL) and certain types of non- Hodgkin lymphoma (NHL), in some respects [7].

CRISPR-Cas9 is found in bacteria and archaea which is found on the event of type 2 acquired immune systems in archaea and bacteria that are used to protect the archaea and bacteria from bacteriophage and the plasmid which acts as a cellular invader. CRISPRCas9 systems has diverse groups, but the most studied system is type 2 CRISPR-Cas9 which is used to modify the genome in eukaryotic systems $[8,9]$. Moreover, the cancer patients have been shown hopeful results by following chimeric antigen receptor (CAR) T cell treatment and Engineered T cell receptor (TCR) technology [10,11]. All these successful results were reported in the time of B cell malignancies' treatment. Solid tumors can be hardly removed which contain complex inhibitory receptors. The activity of T cells is hampered by exhaustion when the patients are affected with chronic infections and cancers. The CAR-T cell therapy can be used to remove solid tumors. The resistant properties of T cells increase the activity of CAR-T cell for removing solid tumors. The CRISPR-Cas9 technique was used as genetic alteration and multiple genomes editing tool $[12,13]$

This current review article explains the importance of diverse immunotherapy strategy but the $\mathrm{T}$ cells are effectively damaging malignant cells. It is important to note that $\mathrm{T}$ cells can be modified using the highly efficient genome editing tool CRISPR-Cas9 for the target of increasing the function of T cells for cancer treatment. CRISPR-Cas9 system exhibits a great result in cancer treatment by editing the cancer genomes, removing or reducing the activity of carcinogenic viral infections. The CRISPR-Cas9 system can be used to modify or alter gene with high efficacy. It is also used as safe and stable methods for cancer treatment rather than traditional treatment. This technique is also used to establish the fitness of edited cells and raise immune cell more responsive. All the above-mentioned advantages, we are mostly focusing CRISPR-Cas9 technology for immunotherapy in cancer treatment through modification of T cells.

\section{Activation of $\mathrm{T}$ cell for recognizing the cancer antigens}

Predominantly in the human blood circulating system, the T lymphocytes are account for approximately 80 to $90 \%$ whereas the other 10 to 20 percent is B cells. In the blood stream, T-cells are assigned to immunity at the cell level of the tissue, while B-cells 
have dual responsibility for both tissue and bodily fluid immunity. A diverse group of cells like $\mathrm{T}$ helper cell and $\mathrm{T}$ toxic cell belongs to $\mathrm{T}$ cell together and execute different types of function to boost immune system in the body. Besides, the indirect immune response is induced by releasing cytokines that are carried out via T cells. At the same time, a group of T cells is stimulated to the antigen-presenting cells (APCs) of the inborn immune system. However, some of the T cells enhance the activity of $B$ cells just because of stimulating the intrinsic response. Furthermore, it can identify an antigen in some cases when a lymphocyte comes into contact with the antigen in its living state.

\section{1. $T$ cell activation:}

$\mathrm{T}$ cell is activated by an antigen-mediated process that is responsible for cellular progression and transformation of primary $\mathrm{T}$ cells into matured cells. This process happens via primary signals and its co-activating signals later it triggers the intracellular signal transduction cascades that cause new gene expression. Antigen-presenting cells (APC) have a protein on their cell surface that attaches to the T cell receptors (TCRs) and this complex of protein and receptor is known as signal phase- 1 in the case of $\mathrm{T}$ cell activation. Besides, the major histocompatibility complex (MHC) molecule of the antigen-presenting cells (APC) (Figure 1) attach to the T cell receptors [14]. Signal phase-2 of the T cell activation happens when the costimulatory proteins attach to the co-activating molecules of $\mathrm{T}$ cell on the surface of APC. In this cascade, the most significant protein B7 executes an important role by activating the $\mathrm{T}$ cell as $\mathrm{B} 7$ protein attaches to the costimulatory proteins of the the T cell. T cells cannot damage the body's own proteins as B7 protein is not produced in the normal cells of the body [15]. When MHC-1 attaches to the cytotoxic (CD8) $\mathrm{T}$ cells then it is activated and plays a crucial role in the lysis of target cells. On the other hand, the helper (CD4) T cells are activated by attaching the MHC-II which results in multiple downstream effects [16]. Body's immunity is regulated by CD4 cells as well as complex and normal immune activities. A group of scientists has demonstrated that CD4 cells are reduced in numbers or do not work in AIDS patients. In contrast, the CD4 cells can overproduce inflammatory cytokines when CD4 cells are more effective [17]. 

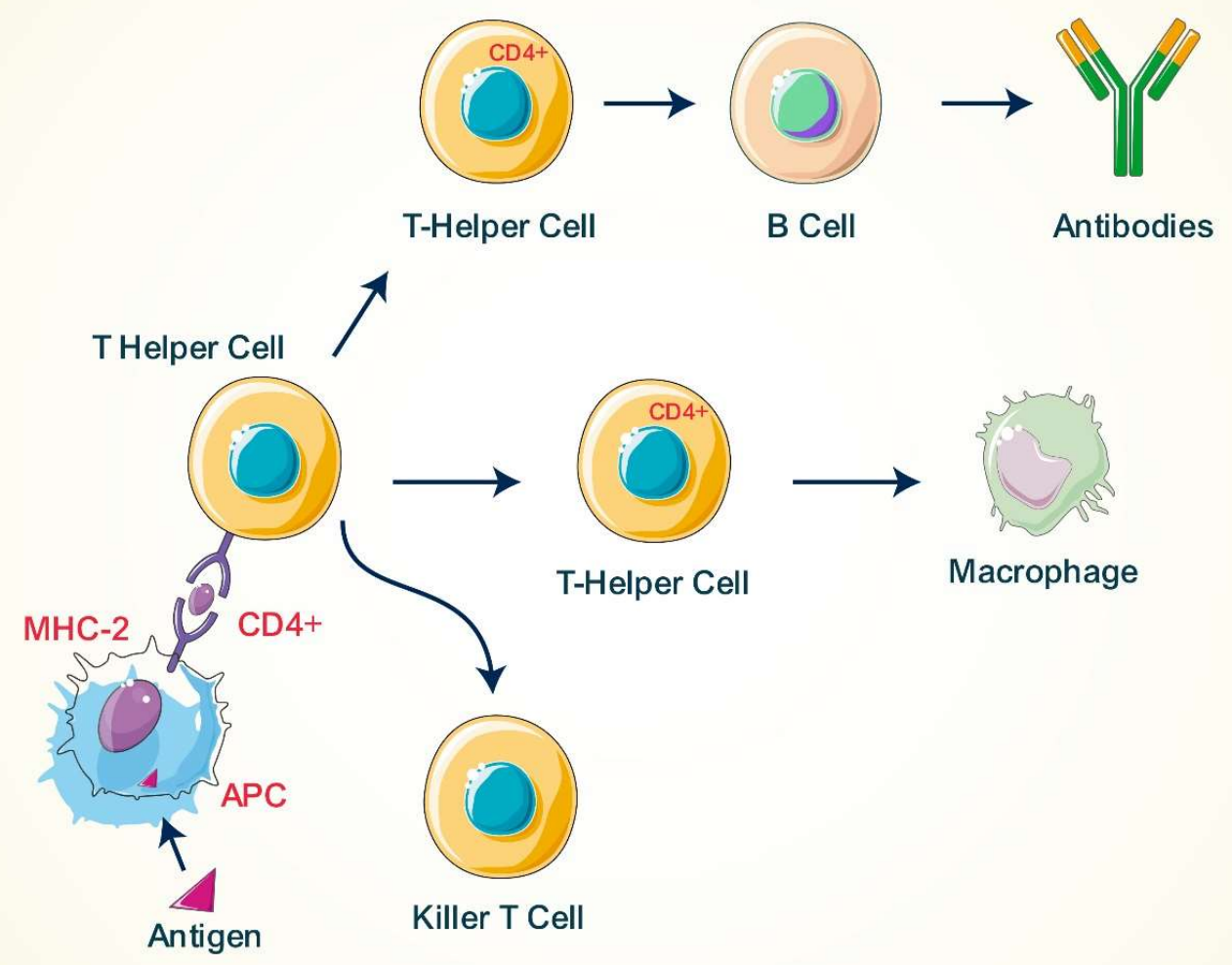

Figure 1. The Antigen-mediated T cell activation process. Antigen bind to a protein present on the surface of the APC and, activate the signal phase-1. Following, signal phase-2 activated by attaching the MHC-2 with T cell receptors and activated the T cell [18].

Table 1. The types of malignancies with their target antigens and their endo domains. Summary of solid tumor antigens targeted by CAR-T cell therapy. .

\begin{tabular}{|c|c|c|c|}
\hline Target Antigen & Malignancies & Endo domains & References \\
\hline $\begin{array}{c}\text { Epidermal growth factor recep- } \\
\text { tor }\end{array}$ & Gastric cancer & & [19] \\
\hline HER2 & $\begin{array}{c}\text { Sarcoma, Glioblastoma, Osteo- } \\
\text { sarcoma }\end{array}$ & CD28-CD3 $\zeta$ & {$[20]$} \\
\hline IL13R $\alpha 2$ & Glioblastoma & $\mathrm{CD} 3 \zeta$ & [21] \\
\hline GD2 & Neuroblastoma & $\mathrm{CD} 3 \zeta$ & {$[22,23]$} \\
\hline FAP & Colon and ovarian cancer & $\mathrm{CD} 8 \alpha, \mathrm{CD} 3 \zeta, 4-1 \mathrm{BB}$ & [24] \\
\hline MSLN & $\begin{array}{c}\text { Pancreatic cancer, Malignant } \\
\text { pleural mesothelioma }\end{array}$ & $\mathrm{CD} 3 \zeta$ and $4-1 \mathrm{BB}$ & {$[25]$} \\
\hline
\end{tabular}

Table 2. Antigens and type of cancers they cause. Tumor antigens classification depends on their molecular structure and their origin also and based on these properties, we can classify the tumor antigen into following categories of TAAs: (i) Mutation products of specific genes (In breast cancer, the mutation of Her2 and Ras causes 10\% of the carcinomas) (ii) Oncogenic virus antigens (iii) abnormal cellular proteins (iv) Types of oncofetal antigens (v) Classes of glycolipids and glycoproteins (vi) Types of differentiated tissue specific antigens .

\begin{tabular}{ccc}
\hline Antigens & Type of Cancer they Cause & References \\
\hline NY-ESO-1 & Esophageal Squamous Cell carcinoma & {$[26]$} \\
MAGEA-A3 & Melanoma & {$[27]$} \\
WT1 & Acute Myelocytic leukemia & {$[28]$} \\
hTERT & Viral mediated Cancer & {$[29]$} \\
Tyrosinase & Brain and Skin Cancer & {$[31]$} \\
gp 100 & Melanoma & {$[31]$} \\
MART-1 & Melanoma & {$[31]$} \\
Melan A & Melanoma & \\
\hline
\end{tabular}




\section{Importance of $\mathrm{T}$ cell in cancer treatment}

T lymphocytes are originated to the bone marrow and its maturation process is regulated in the thymus gland, which plays significant role in body's immunity and fight against the cancer cells. In the human body, there have three types of immune cells which fight to damage cancer cells known as the T cells (thymus-dependent cells), the B cells (bone marrow-mediated cells), and the natural killer cells (NK cells). Importantly, diverse types of T cells which are responsible to damage the cancer cells such as the cytotoxic Tcells, helper T-cells, regulator T-cells, natural killer cells and memory T-cells. In the Table 1 and Table 2 data included the types of malignancies with their target antigens, their end-domains and the antigens and type of cancers they cause. Moreover, the killer-T-cells directly damage the cancer cells and these cells are animated to damage cancer cells when they first reach to the cancer cells. The helper-T cells indirectly help the other immune cells to damage the cancer cells [32]. There are about five million T cells in a teaspoon of our blood which are involved to fight against various foreign toxic substances to keep our body healthy. These amorphous blobs move around quite rapidly pushing out their leading edge and probing their environment as they go [33]. After finding a cancer cell, the cytotoxic t cell checks for the tell-tale sign of cancer. They kill their targets using poisonous proteins. Then those cytotoxic granules move down special pathway in the cell called microtubules. The T cells puncture the surface of the cancer cell and deliver its deadly cytotoxins. This is very important for our bodies as it focuses the lethal hit on the target and minimizes collateral damage to the neighboring healthy cells [34]. The strategies of damaging the cancer cells by the $\mathrm{T}$ cells are regulated by many miscellaneous mechanisms.

T cell therapy for cancer treatment mainly relies on the ability to genetically engineer cells with targeted antigen specificity and then induce the cell to proliferate by preserving their effector function and homing abilities. Mouse models usually have been used for identification and preclinical optimization of tumor therapy nevertheless no mouse models have been found which can be used as good predictor of successful human response to immunotherapy. On the recent time, substantial limitations in some mouse models have been found which have important indications for T cell cancer therapy. In particular cases, it is reported that many mouse tumor antigen do not represent human tumor antigen [35] which has led to strategies to generate transferred human T cell with appropriate specificity of tumor. T cell therapy can be used as efficient treatment for viral infections and early stage of cancer. Recent studies such as cellular immunology and tumor biology showing new strategies to adoptive $\mathrm{T}$ cell therapy. For example, by using engineered $\mathrm{T}$ cell is being tested as a strategy to increase the function of memory $\mathrm{T}$ cells and effector $\mathrm{T}$ cells through manipulating the host to suppress immune toxic effect in tumor microenvironment with a promising result in early stage of clinical trials. Many research studies have reported that using the $\mathrm{T}$ cell for cancer treatment shows an effective result and plays the significant role in cancer therapy. Adoptive T cell therapy is used for the goal of eliminating tumor and its recurrence which consists of various mature T cells. Lymphocyte with inhibitory effect on the growth of cancer cells were observed in many patients which acts as potential candidates for immunotherapy [36]. The main advantages of usages $\mathrm{T}$ cell for immunotherapy for cancer treatment instead of other cytolytic cells, such as NK cells, is that T cells have the ability to bind specifically on target tumor cells by the recognition of differentially expressed tumor proteins which are presents on cell surface. As the $\mathrm{T}$ cells have long clonal life span, it allows both immunoprophylactic and therapeutic sceneries which is also a great advantage for cancer treatment. Moreover, $\mathrm{T}$ cell can be used as well suited for genetic manipulation which enables the evaluation of genetically enhanced $\mathrm{T}$ cell for cancer and other diseases also. For all the following cases $\mathrm{T}$ cell is most important for cancer treatment.

\section{The causes of $\mathrm{T}$ cell failure for recognizing the cancer antigens}


The immune system plays a vital role against cancer cells. It always has searched the diseases and imperfect cells for damage as its target cells. Most of cancer patients possess a weak immune system that's why specific cancer cannot be detected by the body's immune cells [37]. As T cell possesses weak activity in some cases, the cancer cells may evade the defensive immunity and causing primary reason of cancer development. The excessive occurrence of free radicals and protein oxidation in the body cause the DNA damage [38] which also reduce the potential activity of $\mathrm{T}$ cell to effectively recognize the cancer antigens. For example, the CHOP protein (C/EBP-homologous protein) is involved in cellular stress response and myeloid immune cell response [39]. Besides, the tissue of ovarian cancer patient's express more CHOP than normal healthy tissues. $\mathrm{CHOP}$ protein can alter the immune system to form cancer. The activities of CHOP protein of $\mathrm{T}$ cells have been determined by researchers on mice models via a comprehensive set of laboratory trials [40]. Also, CHOP level is increased when T cell is activated and CHOP also causes a negative $\mathrm{T}$ cell regulation process. Anti-tumor $\mathrm{CD}^{+} \mathrm{T}$ cell immunity is developed when the $\mathrm{CHOP}$ gene of $\mathrm{T}$ cells is detected. In normal conditions, $\mathrm{CHOP}$ helps to balance antitumor T-cell response [41]. Moreover, tumors can alter the general activities of CHOP to decrease T-cell immunity. A small number of immune systems permit cancer cells to bypass antitumor immunity activities of T-cells which cause cancer outgrowth and development [42]. There have several others factors that inhibit the T cell's immunity such as the low production of (IL-2) Interleukin-2, an abundance of pro-inflammatory cytokines, the highgrade chronic infection, $\mathrm{T}$ cell exhaustion, etc. Through the mechanism of $\mathrm{T}$ cell exhaustion, the dysfunction of the $\mathrm{T}$ cells which is mainly happened in various types of chronic diseases and also in cancers [43]. Furthermore, it is also a condition of poor effector action and sustainable expression of inhibitory receptors. Exhausting of T cells inhibits optimal monitoring of infections and tumors. The over expression of inhibitory receptors is found by the exhausted $\mathrm{T}$ cell in the tumor microenvironment which will reduce the effector cytokine production and also the cytolytic activities, thus it removes the cancer cells from the body [44]. The activity of exhausted $\mathrm{T}$ cells is lost which is identified by an altered transcriptional program. PD-1, Cytotoxic T-lymphocyte antigen 4 (CTLA-4), lymphocyte activated gene-3 (LAG-3), and domain-containing protein-3(TIM-3) have been reported for causing an important role in T cell exhaustion. The $\mathrm{T}$ cell exhaustion can be reversed by blocking the PD-1 or CTLA-4 checkpoint. By following this system, the T cells become resistant to the different inhibitory pathways.

\section{The current immunotherapies which are used in cancer treatment}

In the branch of cancer biology, current cancer immunotherapy possesses the potential activity against the cancerous cell's throughput the augmentation of the body's immunity. Tumor antigens have found on the cell surface of tumor cells that encounters the antibody but the self-antibody disable to destroy the cancer cells. In this manner, we need modified immunotherapeutic antibodies that potentially encounter against the tumor cells and management the metastasis of cancer [43]. Here we illustrated major approaches of cancer immunotherapy and demonstrated the mechanism how they are followed to treat a wide variety of cancers.

\subsection{Adoptive cell therapy}

Adoptive cell therapy is a form of treatment strategy in which uses the cells of our immune system to eradicate the cancer of our body and mainly known as cellular immunotherapy. In cellular immunotherapy approaches directly involve the isolating of our own immune cells and simply increasing their numbers, whereas others require gene therapy for genetically engineering of immune effector cells due to enhance their anti-cancer capabilities [44]. Significant cancer immunotherapy approaches are illustrated here asTumor-Infiltrating Lymphocyte (TIL), Engineered T cell Receptor (TCR), Chimeric Antigen Receptor (CAR) T cell, Engineered Natural Killer cell (NK) therapy.

5.1.1. Tumor-infiltrating lymphocyte (TIL) 
Naturally occurring $\mathrm{T}$ cells are powerful immune cells in our immune system that engage to fight against cancer cells but the "killer like T cells", are enable to recognizing and alleviate the cancer cells in a very particular way. For effectively killing cancer cells and activity for a durable period to sustain an effective anti-tumor response need harvests the killer T cells in ex vivo expansion that have already infiltrated from cancer patients along with activates and expands the T cell numbers. Potentially activated huge amount $\mathrm{T}$ cells are re-infused into patients finally that can directly encounter and destroy tumor cells [45]. Recent Clinical reports proposed that tumor infiltrating lymphocytes (TILs) have extensively used for patients who develop solid tumors, metastatic melanoma, ovarian cancer, renal cell carcinoma, colorectal cancer, pancreatic cancer and so on cancers [46].

\subsubsection{Engineered $\mathrm{T}$ cell receptor (TCR) therapy}

In some case $\mathrm{T}$ cells are dis-able to encounter the advanced form of cancer so, we requisite engineered $\mathrm{T}$ cell receptor for action against solid tumors. For this approach taking $\mathrm{T}$ cells from cancer patients and introduce the engineered novel receptors that enables them to target specific cancer antigens, tumor lysis and eradicate the tumor cells. Here we declared that engineered $\mathrm{T}$ cell play outstanding functions and their actions in longevity in the tumor microenvironment [47]. Engineered T cell receptors (TCRs) composed the $\alpha$ and $\beta$ chains that are associated with $\delta, \varepsilon$ and $\gamma$ chains and the most signaling region of this receptor known as $\zeta$ chains. Herein, novel $\mathrm{T}$ cell receptors encounter the tumor antigen via the MHC-I/MHC-II and advantages of Engineered T cells to identify suitable target antigens, overcome immunosuppressive tumor microenvironments, prevent antigen escape and reduce toxicities [48].

\subsubsection{Engineered natural killer (NK) cell therapy}

Augmenting the capability of NK cell antitumor responses via the introduction of antigen specificity by using genetic modification. Herein, CAR-NK cells basic structural framework has similarity to CAR-T, mainly CAR composed of extracellular, hinge, transmembrane as well as intracellular domains. The extracellular domain of CARs is ScFvs interact with the hinge domain and the transmembrane domains connected between the hinge and intracellular domains like- CD3 $\zeta$ and/or CD28. In addition to that fact, CARmediated NK cell requires co-stimulatory molecule as- CD28, 4-1BB, CD134 in order to increase the proliferation and cytotoxicity effect against the solid tumor [49]. The cuttingedge approaches (CAR-NK therapy) might be the potential substitutes for the existing time-consuming technology CAR-T cell therapy. Here, CAR-NK cell therapy is more significant due to some basic criteria for examples- less expensive, easy to be isolated, secreted more safer cytokines (IFN- $\gamma$ and GM-CSF) [50].

\subsubsection{Chimeric antigen receptor (CAR) T cell therapy}

CAR T-cell therapy depends on efficient, stable and safe gene transfer platforms. Cancer patient T-cells isolated through leukapheresis that are harvested and genetically modified ex vivo expansion through viral and non-viral transfection methods. The CAR $T$ cell consists of the extracellular antigen binding moieties could be a single-chain fragment variable $(\mathrm{scFv})$ portion consists of the variable heavy $(\mathrm{VH})$ and variable light (VL) chains of an antibody, fused by a peptide spacer and it is interlinked to an intracellular

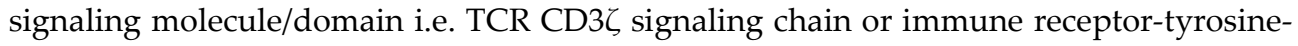
based-activation-motif (ITAM)-containing protein that are bind with tandemly co-stimulation signals like- CD28 or 4-1BB [51]. The inauguration of CAR T cell therapy for the recognition of unprocessed antigens, carbohydrate as well as glycolipid structures which are represent on tumor cells surface. However, both types of CAR T cells like- CD4+ and/or CD8+ T cells recruited and redirected to the target Site of cancer without the expression of MHC-I and MHC-II. These two effective T cells perform the major killing mechanism as-cytolysis via the perforin and granzyme secretion and in some cases follow the death mechanism by expressing the Fas/Fas-ligand (Fas-L) and/or TNF/TNF-receptor (TNF-R) [52]. Feins S et al (2019) also illustrated that CAR T cells act against the CD19 
protein of tumor cells of acute lymphoblastic leukemia and diffuse large B cell lymphoma and these $\mathrm{T}$ cells therapy used for the treatment of thus cancers. Here, we outlined the ameliorate proliferation, cytotoxicity, sustain response and durability of CAR-T cells for the treatment of leukemia and lymphoma [7].

\subsection{Immunomodulators}

Immunomodulators are directly interlinked to modification of the immune system along with these stimulatory molecules enable checkpoint blockers [53], enhance cytokines secretion and act as an agonist for blocking the cancer progression and enhancing the potential activity of immune cells. Basically, Cytotoxic Tlymphocyte-associated antigen-4 (CTLA-4) manifested on the surface of T cells and regulatory T cells (Tregs) and the CTLA-4 counteracts the activity of the T cell co-stimulatory receptor (CD28). After recognition of antigen the CD28 molecules strongly amplitude TCR signaling for the $\mathrm{T}$ cells activation. Here we clearly said that the CD28 and/or CTLA-4 represent identical ligands like- CD80 and CD86 [54]. Notably, CTLA4 has higher affinity for both ligands (CD80 and CD86) and expression of the ligands on the surface of T cells dampens the activation of T cells by outcompeting CD28 in binding CD80 and CD86, as well as actively delivering inhibitory signals to the $\mathrm{T}$ cell [55]. On the contrary, programmed death-1 (PD-1)/ programmed death ligand-1 (PDL-1) play crucial role in tumor progression and survival of tumor in the tumor microenvironment. Mainly, PD-1 is found on a several immune cells like- T cells, B cells, dendritic cells as well as monocytes [56]. Tumor cells and antigen presenting cells expressed the PDL- 1 and interact the T cells PD1 and may develop $T$ cell dysfunction, neutralization and exhaustion. It has been reported that PDL-1 is expressed on the tumor cells and escape the cytotoxic T cell mediated cell killing and develop tumor mass in the body [57]. However, when checkpoint inhibitors inhibited the pathway of PD-1/PDL-1; CTL-4, they can capable T cells to inhibit the advancement of tumor mass.

Cytokines are proteins or glycoproteins released by the specific cells of our immune system that mediate the immunity and directly modulate the immunomodulatory cells. The immunostimulatory cytokines that are potentiate immune responses against cancerIFNs $\alpha$, IL-2, IL-12, IL-15 and IL-18 [58]. The major cytokine IL-2 is capable to promote the expansion of helper T cell (CD4+ T), NK cells and facilitates the synthesis of Ig type antibody. The crucial role of IL-2 is Fas-mediated activation of CD4+ T cells that is induced the cancerous cell death [59]. (2004) [60] reported two major cytokines as namely- IL-4, IL7 directly engage the enhancement of T cell function but the IL-4 followed to activation of eosinophil and eradicate the cancer cells from the body. IL-15 is needed for the activation, proliferation, cytotoxic action of NK cells and $\mathrm{CD} 8^{+} \mathrm{T}$ cells, which are capable to release of cytokines like- IFN- $\gamma$ and followed the potential antitumor activity. Importantly, IFN- $\alpha$ is specialized cytokines to use for the treatment of several malignancies and solid tumors through the maturation of dendritic cells and T lymphocytes [61].

\subsection{Antibody mediated therapy}

Antibodies are proteinaceous compound that protect us from several threats produced by a B cells and act against cell surface markers mainly-antigens. Antibodies likeMonoclonal antibodies (MAbs)have significant cytotoxic effect against a tumor cell surface antigen and modify the signal transduction cascade pathway within the tumor cells through the complement dependent cytotoxicity (CDC) and/or Antibody dependent cellular cytotoxicity (ADCC) [62]. In CDC pathway MAbs directly modulate the classic complement pathway, when the complement component $\mathrm{C} 1$ recognize fragment crystallizable region (Fc region) of antibodies and activate the $\mathrm{C} 3 \mathrm{a}, \mathrm{C} 3 \mathrm{~b}$. The $\mathrm{C} 3 \mathrm{a}$ recruit immune effector cells at the complement activation site, but $\mathrm{C} 5$ convertase activated by the complement component $\mathrm{C} 3 \mathrm{~b}$ via the activation of alternative pathway that form the Membrane attack complex (MAC) to lysis the tumor cells [63]. ADCC is a process, On the contrary, in which specific antibodies bind to the immune effector cells like-monocytes, natural killer cells 
(NK cells) and other leukocytes to kill the antigen specific tumor cells. Therapeutics antibodies engage to the Fc receptor of immune effector cells via the Fc region of antibodies for example- MAbs Fc region attach the Fc $\gamma$ RIII receptors on NK cells for activation and trigger the NK cell to secreted perforin and granzyme result in the death of cancer cells. Besides, NK cells released proinflammatory cytokines due to the recruitment of adaptive immune cells and inhibitory action play against the cancer cells [64].

\section{The other probable strategies for the treatment of cancer}

Within the host body, tumor cells control a variety of techniques for eradicating the body's immunity, including rendering the host body's immunity powerless and generating an environment with immune-suppressive activity. There are numerous treatment strategies available for cancer today, but they all have numerous adverse side effects in the human body.

\subsection{Formation of bi-specific T-cell engaging antibodies for cancer therapy}

Many research activities have been indicated that in both early and late phases of the diseases, the $\mathrm{T}$ cells are capable for controlling the enhancement of tumor development and progression in the cancer patients [65]. But there have some difficulties because of the $\mathrm{T}$ cell responses for tumor specific antigens are complex to aspire and maintain in the cancer patients. Moreover, in the time immune-editing, the responses are confined by some of the immune emission mechanism for the selective tumor cells [66]. The production of antibodies will be an effective strategy to assemble T cells for the immune-therapeutics treatment of cancers and these types of antibodies are expressed only on the surface specific antigen of every type of cancer cells, and for the CD3 complex on T cells. These types of antibodies are efficient to engage any kinds of cytotoxic $\mathrm{T}$ cells to the cancer cells to damage the cancer cells [67].

Independently, it can enhance the specificity of the T-cell receptor, co-stimulation, or presentation of peptide antigens independently. Various research activities have demonstrated that, among bi-specific antibodies derived from T cells, the BITE (for "bi-specific T-cell engager") antibodies have demonstrated promising efficacy in the treatment of both bulky and minimal residual disease [67]. Kufer's and colleagues' research project has shown that the special design of the CD3/target antigen-associated bi-specific antibodies has a very high rate of efficiency and can also involve CD8+ and CD4+T cells to redirect the cancer cell lysis process to the target (E:T-ratio) ratios [68].

When the bi-specific antibodies bind only the CD3-specific branch it shows low efficiency as the monovalent antibodies that cannot trigger the T-cell signaling by CD3 (Figure 2). Contrariwise, the "bi-specific T-cell engager" (BITE) antibody is activated to the T cell through the multivalent strategy by the target cells [69, 70]. In an in-vitro study, the BITE antibody was found to be highly effective at redirecting the damaging of cancer cells. Additionally, it demonstrates the drug's potent antitumor activity in a variety of animal models [71, 72]. In recent, many research activities have been demonstrated that two BITE antibodies named as Blinatumomab (it's also informed as the MT103) is specific for the CD3 and CD19. For testing procedure of stage 1 clinical trial of cancer patients, at late stage who further relapsed with the non-Hodgkin's (NHL) [73]. Moreover, it is also tested as a stage 2 clinical trial of the cancer patients who possessed the b-precursor acute lymphoblastic leukemia (B-All) and show minimum accessorial disease in the patient's bone marrow [74]. 


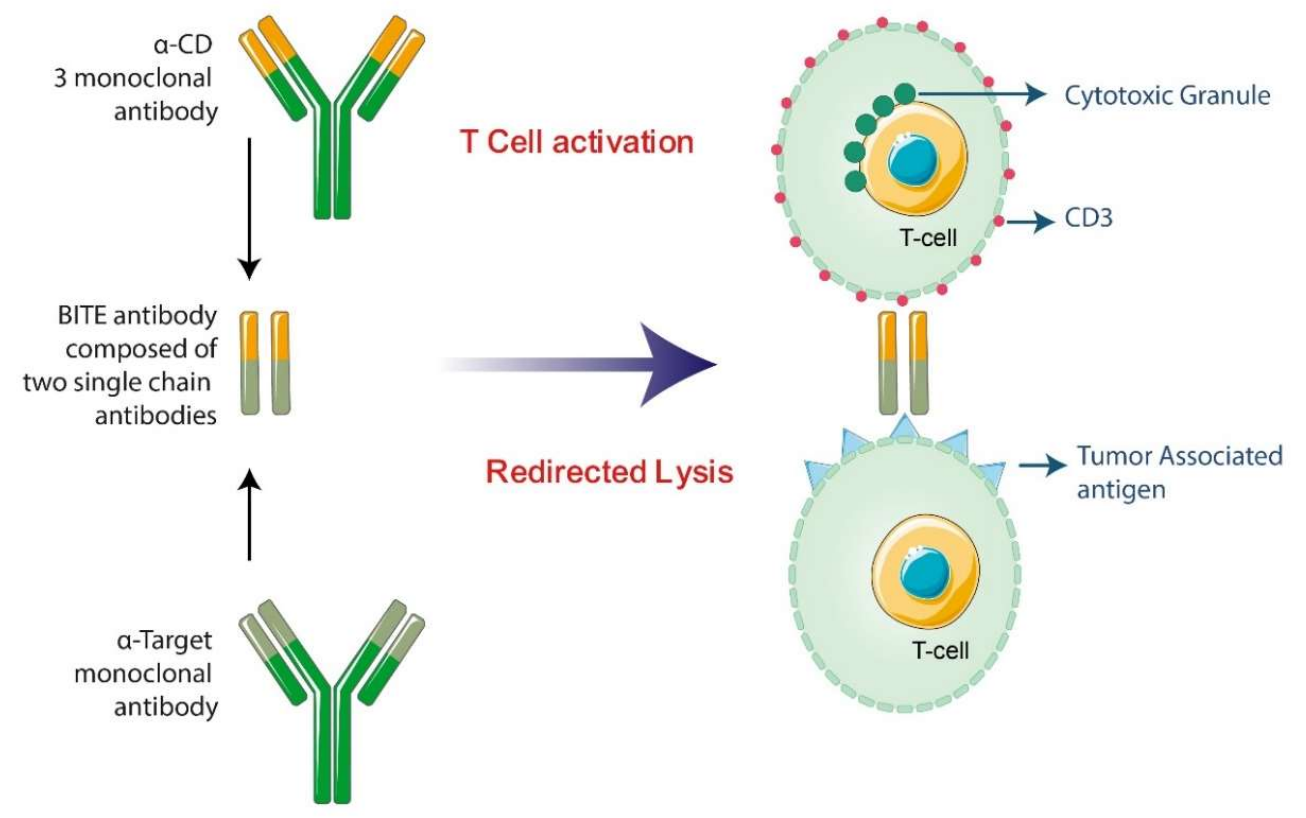

Figure 2. Formation of bi-specific T-cell engaging antibodies for cancer therapy. Bi-specific antibodies with only CD3 showed the low efficiency of $\mathrm{T}$ cell signaling. On the other hand, through the multivalent strategies "Bi-specific T-cell engager" (BITE) antibody activated the T cell.

Another BITE antibody named as the MTT110 which is in now the clinical development phase and it is bi-specific only specially for the CD3 complex and the epithelial cell adhesion molecule (EpCAM) [75]. It is currently being clinically tested in patients with lung and gastrointestinal cancer as part of the clinical trial one. The expression efficiency of the epithelial cell adhesion molecule (EpCAM) is therefore high on several squamous cell carcinoma types, human adenocarcinoma and cancer stem cells efficacy was shown. It has certain limitation because the model animal did not identify the CD3 modulation of T-cells by treating BITE antibodies to suppress the cytotoxic granules of T-cells [76].

\subsection{Formation of cancer vaccine}

Cancer treatment vaccines enhance the immune system's capability to signify and damage the cancer antigens more effectively. Cancer cell possesses specific molecules named cancer specific antigens for every types of cancer cells on their cell surfaces but it is absent in the healthy cells. Mainly the cancer vaccines can be produced for the individual cancer patients. These categories of cancer vaccines are composed from the tumor sample of the individual cancer patients (Figure 3). For that indeed, the surgery is required to find a massive enough sample of the tumor cells to make the vaccine against these cancer cell. There have two types of vaccine in cancer treatment. They are the personalized cancer vaccine and the vaccine for the target specific cancer antigens. 


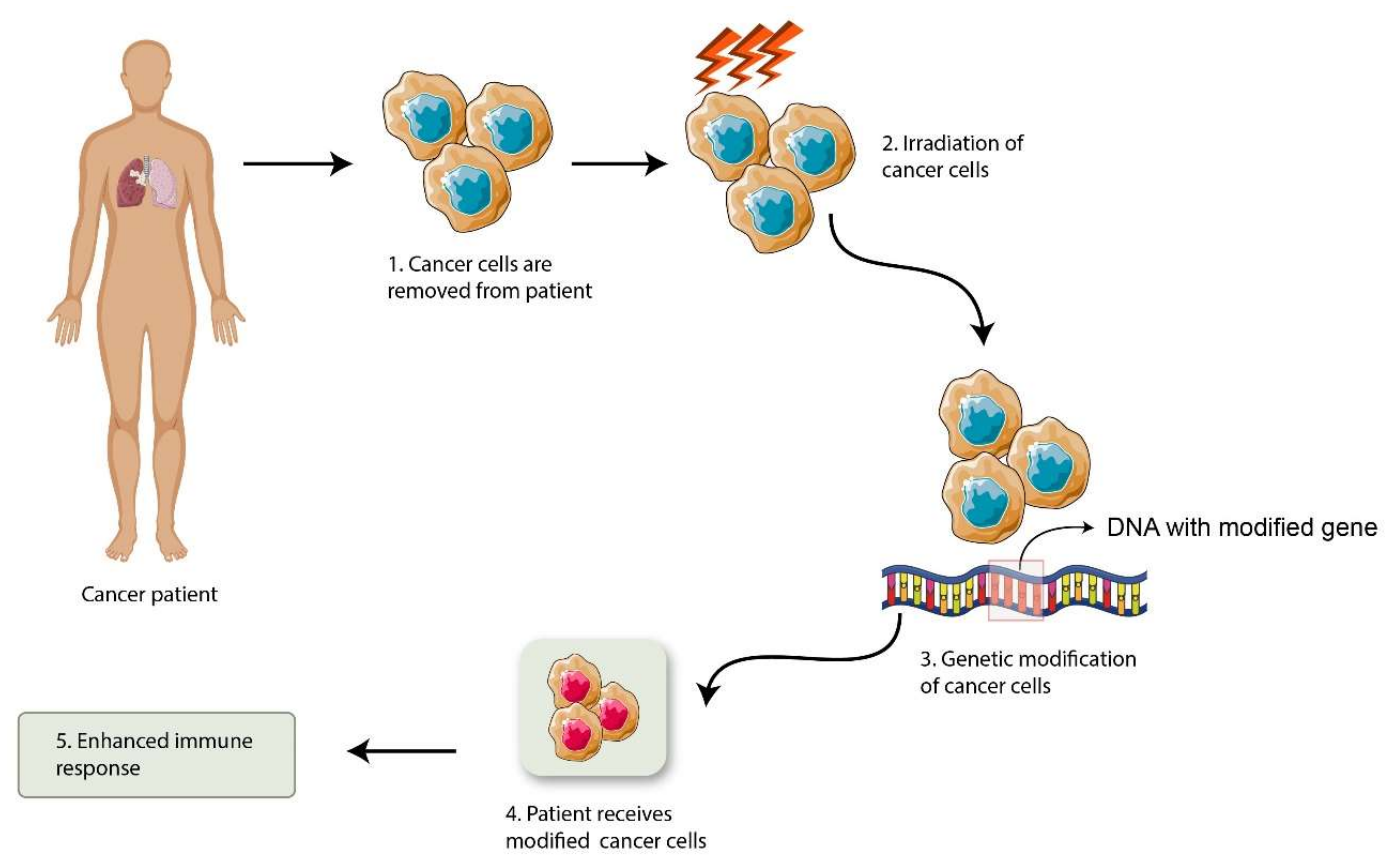

Figure 3. The steps for the formation of cancer vaccine. A surface protein found on the surface of cancer cells and vaccine developed depending on the structure of that protein. Here, the DNA with modified gene will be inserted into the cancer cells by genetic modification through using the irradiation to the cancer cells.

Even if the cancers can be originated by the common mechanisms, that is regulated by the mutated genes in the process of cell transformation (i.e., p53, ras), they pass through excessive random mutations in other genes. The expression of foreign antigens is regulated by these mutations and making a molecular 'fingerprint' that absolutely distinguishing the patient's tumor. Whereas, the mutations of genes are regulated indiscriminately, the antigenic fingerprint of one person's cancer is generally not same to the other person's cancer. In this way the particular cancers among the identical pathological group are independent based on their antigens. These essential characteristics demand that the immune system of individual patient's has to be treated to signify the specific cancer antigens and cancer cells. This is the novel approach for generating a cancer immune-therapeutics through using the patient's personal cancer cells [77]. The cancer vaccine possesses an effective activity to provide the immunity towards the cancer antigens. The response stimulates the activity of antigen presenting cells (APCs) for triggering the functions of Thelper cell to provide the antibody against the cancer antigens and also activate the effector or cytotoxic T cells. But in cancer vaccine, it's had some limitations, because the tumor cells or cancer cells express the random specific types of antigens, these antigen's type is not fixed. For that reason, the cancer vaccine is not so effective for inhibiting the growth of the cancer cells.

\subsection{By blocking excessive activity of $\mathrm{CHOP}$ protein}

The C/EBP is mainly the CHOP protein The homologous protectin, also known as the CADD153, stimulates the transcription process and expresses the $\mathrm{CHOP}$ protein at different levels during endoplasmic reticular stress (ER) [78] and in the animal body, the endoplasmic reticulum (ER)-stress induce the apoptotic pathway [79]. The $\alpha$-subunit of eukaryotic translation initiation factor (elF2 $\alpha$ ) is phosphorylated through the endoplasmic reticulum (ER) stress-activated kinase PERK $[80,81]$ and decreased the attendant in elF2 activity dramatically induces the $\mathrm{CHOP}$ promoter [82]. The explicit expression to the other components of the unfolded protein receptor (UPR) is received by the CHOP promoter and the p38 kinase finally induce the post-translation process of the CHOP protein activation or CHOP protein folding $[83,84]$. In this review research article, our aim is that it 
will be effective to cure from the tumor-induced CD8+ T cell suppression if we can suppress the excessive activity of CHOP protein or endoplasmic reticulum (ER) stress. Because blocking the CHOP protein's excessive activity or endoplasmic reticulum (ER) stress enhances the efficacy of T cell-based immunotherapy.

\subsection{Through inhibition of $T$ cell exhaustion}

T-cell exhaustion is known as T-cell dysfunction that occurs in many chronic infections and cancer which is also a condition of poor effector action and sustainable expression of inhibitory receptors [85]. Exhaustion of T cell inhibits optimal monitoring of infections and tumors in which the over expression of inhibitory receptors was found in tumor microenvironment which reduced the effector cytokine production and also the cytolytic activities and resulted the exhausted T cell, thus it happens the failure event of the removal of cancer cells. The mechanisms for the T cell abnormalities are not clearly known to all. In order to solve these abnormalities, the gene expression was observed in the virus specific CDRT cell line of mice which was functionally weaken and chronically infected with lymphocytic choriomeningitis virus (LCMV). It was showed that PD-1 (programmed death 1) was up-regulated by the exhausted T cell [86].
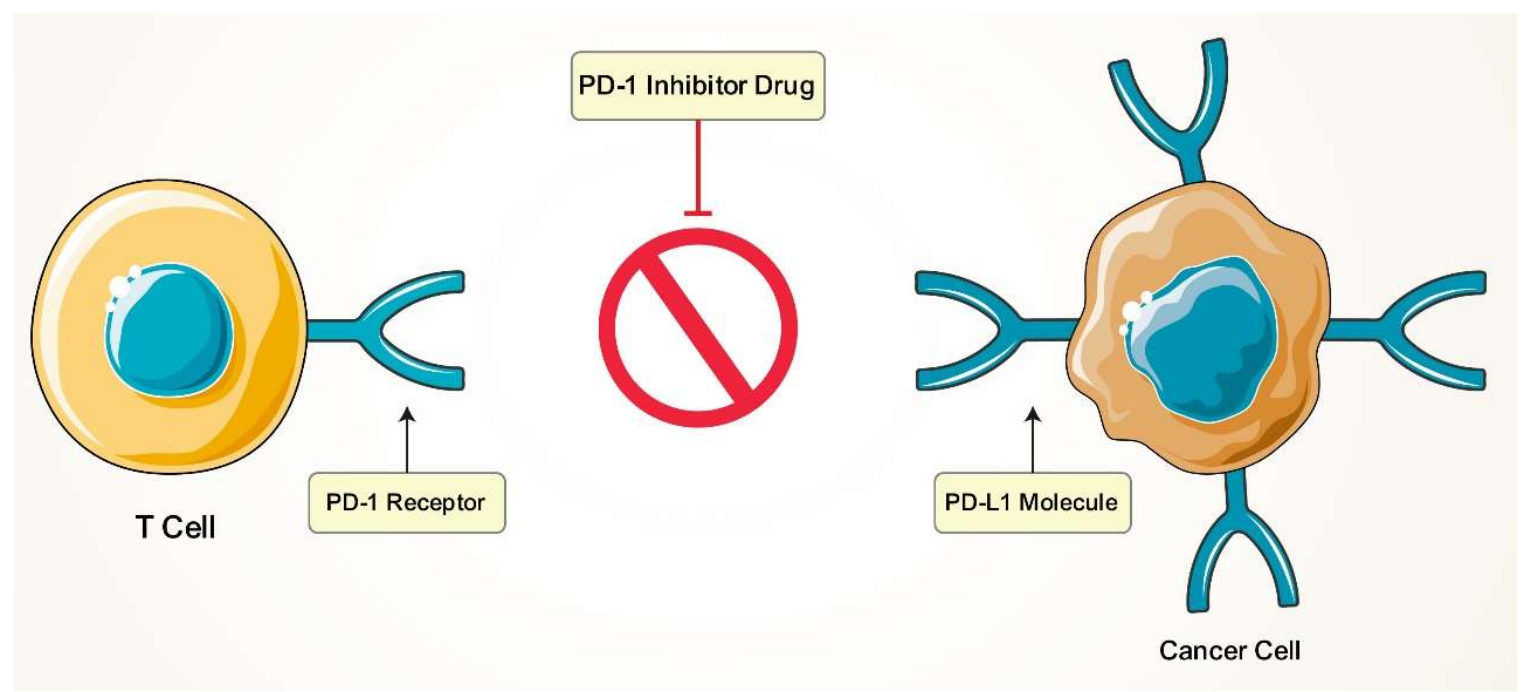

Figure 4. The mechanism of getting back the exhausted $\mathrm{T}$ cell into activated $\mathrm{T}$ cell against cancer cell. By showing a molecule called PD-L1, the normal cells send white flag to the immune system. The signal is detected by T cells via PD-1 protein. The protein binds with PD-L1 and prevent T cells from attracting body's own cells. By coating themselves in PDL1, a few numbers of cancer cells deceive the immune system. The inhibitor drugs stop this process that allows immune system to fight and kill cancer cells.

However, the promotion of $\mathrm{T}$ cell functions occurs when its inhibitory receptor is interconnected with its ligand and the ligand PD-L1 (known as B7\&-H1) was blocked by antibodies (Figure 4). Thus, by blocking of PD-1/PD-L1 inhibitory pathway the CD8T cell is restored and they are now able to proliferate, secrete cytokines and destroy the infected cell [87]. In contrast, $\mathrm{T}$ cell exhaustion can also be eliminated through engineered $\mathrm{T}$ cells in the event of lethal diseases and cancer [88]. The expression of PD-1 can also be degenerated by genome engineering strategies instead of blocking the PD-1/PD-L1 mechanism. The process can be completed by CRISPR/Cas9 system [89]. By using CRISPR/Cas9 system, it was reported that the expression of PD-1 on the primary human cells was reduced. Thus, it shows an effective strategy to generate the CAR-T cells which are resistance to exhaustion [90]. So, by following the two above mention methods, the exhausted T cell can be restored. The cancer treatment could be an inspiring event by restoring of these exhausted $\mathrm{T}$ cell, that can produce provide a hopeful result and it may become important breakthrough in Cancer immunotherapy. 


\section{The strategy of $T$ cell modification through using the CRISPR-Cas9 genome editing tool}

By the above demonstration from many research findings, the estimation can be generalized that modification of $\mathrm{T}$ cell receptor could be a possible solution for the effective immunotherapy in cancer treatment in which the genetically engineered $\mathrm{T}$ cells can express the genes of the Chimeric Antigen Receptor (CAR) proteins [91]. The genetic construct of CAR introduced to T cells by transfection with viral vector, mRNA or plasmid by gene editing tool (CRISPR-Cas9) to guide T cells which are aligned with the surface antigens of the tumor cells (TAAs) (Table 1) and the recent development in molecular biology and gene editing tools has also been evolved. The only first-generation CAR

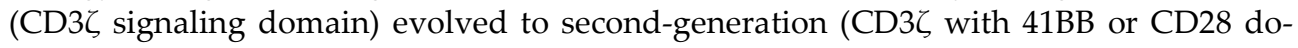
mains) and third-generation (CD3 $\zeta$ with $41 \mathrm{BB}$ and $\mathrm{CD} 28$ domains) CARs which have improved $\mathrm{T}$ cell targeting and proliferation for the addition of the costimulatory endo domains (Table 2). In the human leucocyte antigen molecules, CARs are designed to target particular peptides, which may enable the targeting of intracellular molecules (Figure 5) [92].

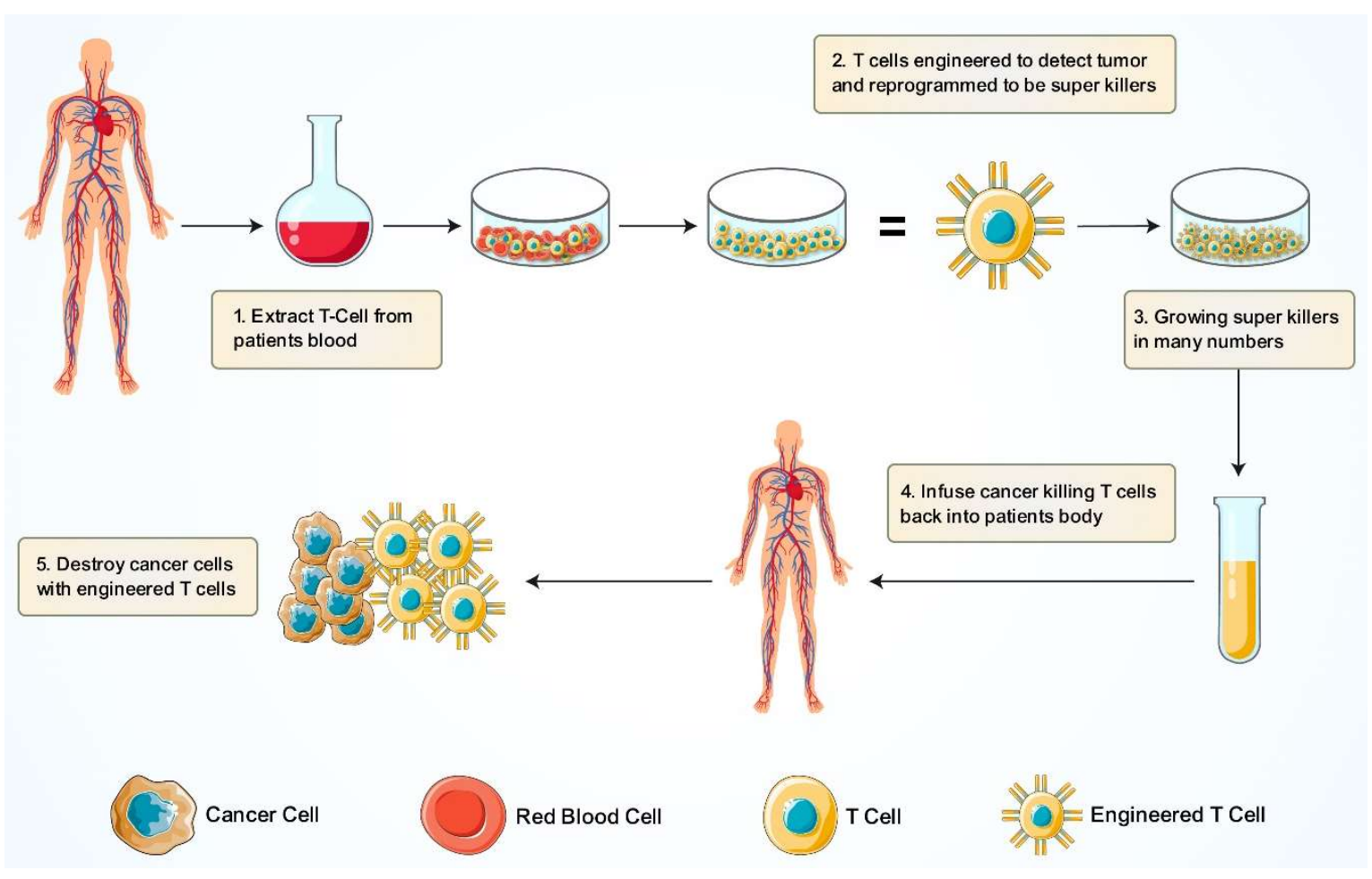

Figure 5. The Process for the production of high efficiency cancer killing T cell. T cells are modified in order to make them more effective to kill cancer cells. For this purpose, the extract of $\mathrm{T}$ cells is taken from patients. $\mathrm{T}$ cells are engineered so that they can recognize tumor cells and then, they are reprogrammed to generate super killer cells. The super killer $\mathrm{T}$ cells are grown into multiple numbers. These T cells are infused back into patient's body to work against cancer cells. Finally, the engineered $\mathrm{T}$ cells can be able to destroy cancer cells.

These modified T cells, which have tumor targeting receptors, were shown to be very promising in clinical trials for multiple leukemia and lymphoma and could be used to treat solid cancer [93]. Genetic modification to generate this potential chimeric antigen receptor can be carried out by the only specific editing tool like CRISPR-Cas9 [94]. Because the alternatives of CRISPR-Cas9 are zinc-finger nucleases (ZFNs) and transcription activator like effector nucleases (TALENs), since the major drawback of ZFNs and TALENS are the recognition of the target DNA sequence is determined by protein sequences [95]. For each particular target DNA sequence, therefore, a laborious and complex process and optimization of protein are needed and it is difficult to deliver many of these proteins in 
cells for simultaneous multiplexed genetic modification [96]. CRISPR system was identified inside bacteria when it was invaded with foreign DNA. In type II CRISPR strategies combines invading DNA sequences and CRISPR repeat sequences that are encoded by bacterial genome. This CRISPR repeat DNA sequence is transcribed and formed crRNAs [97], it includes protospacer which is a variable RNA sequence transcribed and formed crRNAs [84], which is a variable RNA sequence from the invading DNA and CRISPR arrays of host DNA. Every crRNA hybridizes with a second RNA known as the CRISPR RNA (tracrRNA) and then they form complex with Cas9 endonuclease protein which cut DNA $[97,98]$. The crRNA protospacer part directs Cas9 through additional target DNA sequences and cleaves the DNA if they are adjacent to short sequences recognized as protospacer adjacent motifs (PAMs). It was first revealed that the Streptococcus pyogenes Cas9 protein (SpCas 9) would associate the tracrRNA-crRNA RNA complex to induce a double stranded breakage (DSB) in a target DNA sequence [98]. This experiment has also shown that Cas9 does not need an RNA complex to bind and break a certain DNA sequence, rather a constructed single guide RNA can easily achieve this method (sgRNA). The above studies laid the foundation for CRISPR/Cas9 to be used in the field of genome engineering involving genetic modification and control of gene expression, epigenetic alteration, and the imaging of the genome [99-103]. By using a plasmid encoding Cas9 and sgRNA, CRISPR/Cas9 can be applied directly to human cells and there have also been studies of gene editing with non-integrated virus such as adenovirus and adenovirus-associated virus (AAV) [13, 76, 104]. New developments of smaller Cas proteins have allowed and improved the combination of this technology with vectors that have increased their optimization, such as AAV vectors. Efficient gene editing in human cells was also used in CRISPR delivery via Cas9 (Ribonucleoproteins, RNP) [105]. Lentiviral and adenoviral transmission of CRISPR components to primary $\mathrm{T}$ cells resulted in genetic change in T cells.

However, these techniques cannot directly insert and interrupt the basic genetic elements at the location level and have not been successful in genetic modification [106, 107]. Lentiviral CRISPR kit has lately been created with the versatile and simple to operate which is Jurkat $\mathrm{T}$ cell based and this toolbox can provide an additional advantage to research on T-cell signal transductions and programmability with different variants of Cas9 proteins [108]. There is also a study on the gene editing of Cas9 RNP cells at a particular site [89]. However, with in-vitro produced sgRNAs and Cas9 protein (recombinant) form the Cas9 RNPs and this synthetic Cas9 RNPs was introduced inside CD4 T cells and it resulted the specific genetic modification because the treated T-cells did not express PD-1 and CXCR4 proteins. In particular, the successful implantation of DNA inserts by the incorporation of HDR (Homology-directed repair) template at the Cas 9 cleavage position and this was assured by the deep sequencing. 


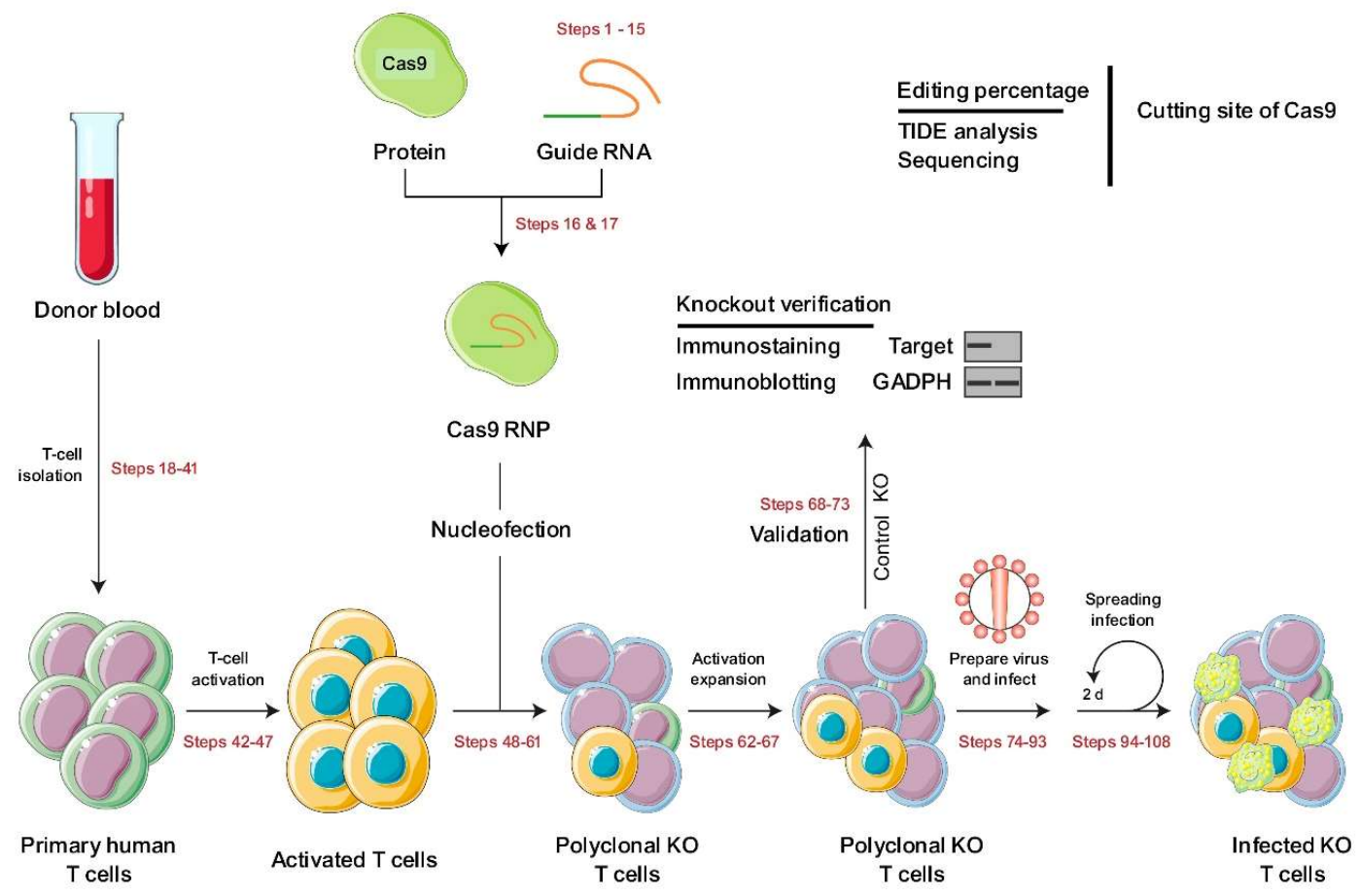

Figure 6. The strategy of T cell modification through using the CRISPR-Cas9 genome editing tool. Here we have depicted the estimated strategy of T cell modification through using the CRISPR-Cas9 genome editing tool. Here, the donor blood cells have to extract to collect primary human T cells, then these cells will be transformed to polyphenols $\mathrm{KO} \mathrm{T}$ cells by our mostly desired CRISPR-Cas9 genome editing tool. After that these genetically modified polyclonal $\mathrm{T}$ cells will be validated by knockout verification and finally injected into the cancer patient body. .

In $55 \%$ of the targeted $\mathrm{T}$ cells there were indels and $20 \%$ exogenous DNA [89]. In another study by Hendel et al was showing that the any modification of CCR5 gene by Cas9 mRNA in T cells with synthetic sgRNAs, can result more success rate where around $49 \%$ of target $\mathrm{T}$ cells were modified at their targeted site and was evaluated with TIDE method by hybridizing indels with fluorescent molecule [109]. There is also a report on the procedure of disrupting DNA in T cells to synthesize clinically standard CAR T cell [110]. Freshly isolated human T-cells have been stimulated with anti-CD3/CD28 beads and lenti-virally-transformed for stable expression of CAR-Transgene at a period of 1 day after stimulation, and $\mathrm{T}$ cells were electroporated simultaneously on days 3 and 4 with RNA encodes Cas9 and SgRNA to cut PD1, HLA-1 and TCR genes [111]. The output using this technique was based on the donor sequence, with results showing $>70 \%$ CAR transduction ability in several production models and also $>60 \%$ dual knockout efficiency which have been briefly demonstrated on the figure 6 . This development process resulted in CAR T cells that were unique to CD19 targets, resistant to host rejections and unable to cause GVHD, for this reason emphasizing on CRISPR/Cas9 mediated universal CAR T cell generation. Similar findings were recorded using a different CRISPR/Cas9 strategy with Cas9 RNPs and targeted the B2m, PD1 and TCR genes [112]. With a single electroporation of different Cas9mRNAs an effective gene alteration can be achieved [113] and this could be less time consuming and success rate could increase. Therefore, these gene editing techniques based on CRISPR/Cas9 can therefore inhibit TLA-4 or PD-1 cells from $\mathrm{T}$ cells, and then targeted tumor cells for successful immunotherapy.

\section{Concluding remarks}

Overall, the new emerging CAR T-cell therapy will be a novel strategy that will increase the activity of $\mathrm{T}$ cells and can be worked as the immune-therapeutics in the treatment of cancer. In this review, we have shown the modification of the T-cell in therapeutic purpose in cancer treatment with the high efficiency genome editing tool CRISPR Cas9, 
specifically its applications in therapeutic purposes against the cancer disease and the development process of $\mathrm{T}$ cell therapy in next generation metamorphosis drugs. The CD19mediated chimeric antigen receptor $\mathrm{T}$ cell therapy will become a novel strategy in the treatment of human cancers. In chimeric antigen receptor (CAR) T cells, an extracellular single-chain variable fragment $(\mathrm{ScFv})$ is specific to the antigens on tumor cells and the $\mathrm{T}$ cell activation is occurred by an intra-cellular chimeric signaling domain. Then the T cells damaged the tumor cells.

In many cancer research activities $\mathrm{T}$ cell role in both early and late phage of disease where $\mathrm{T}$ cells show its functions for controlling the enhancement of tumor development and progression in the cancer patients. But there have some abnormalities for generating the $\mathrm{T}$ cell responses against the tumor specific antigens which is difficult to aspire and maintain in the cancer patients. An effective strategy to add T cells for cancer therapeutic treatments are antibodies. These antibodies are activated only for the surface specific antigen on cancer cells, and for the CD3 complex on T cells. These types of antibodies are efficient to engage any kinds of cytotoxic T cells to the cancer cells to damage the cancer cells. However, for using the CRISPR/Cas9 technology to mediate immunotherapy, we have broadly demonstrated the CRISPR/Cas9 mediated genome engineering strategy which will exhibit a significant impact for the therapeutic potential of this technology, and thus represent a very important area which will help the biological researchers for the future study about this novel strategy for the cancer immunotherapy.

Acknowledgments: This research was supported by Basic Science Research Program through the National Research Foundation of Korea (NRF) funded by the Ministry of Education (NRF2020R1I1A2066868), the National Research Foundation of Korea (NRF) grant funded by the Korea government (MSIT) (No. 2020R1A5A2019413), a grant of the Korea Health Technology R\&D Project through the Korea Health Industry Development Institute (KHIDI), funded by the Ministry of Health \& Welfare, Republic of Korea (grant number : HF20C0116), and a grant of the Korea Health Technology R\&D Project through the Korea Health Industry Development Institute (KHIDI), funded by the Ministry of Health \& Welfare, Republic of Korea (grant number : HF20C0038).

Author Contributions: Conceptualization by M.A.S., P.B. Writing and main draft preparation by M.A.S., P.B., D.D., M.A.K., M.A.I., M.I.A.T., M.Y.B, P.P. Figures drawing by M.H.R., T.I.R. Review and editing by M.A.R., M.N.H., B.K. Visualization and supervision by M.A.R., B.K. The Project Funded by B.K. All authors have revised and agreed to the published version of the manuscript.

Data Availability Statement: The datasets used and/or analyzed during this study are available from the corresponding authors upon request.

Conflicts of Interest: The authors declare no conflict of interest.

\section{References}

[1] Porter DL, Levine BL, Kalos M, Bagg A, June CH. Chimeric antigen receptor-modified T cells in chronic lymphoid leukemia. The New England journal of medicine. 2011;365:725-33.

[2] Riley RS, June CH, Langer R, Mitchell MJJNrDd. Delivery technologies for cancer immunotherapy. 2019;18:175-96.

[3] Mellman I, Coukos G, Dranoff GJN. Cancer immunotherapy comes of age. 2011;480:480-9.

[4] Crowther MD, Svane IM, Met ÖJC. T-cell gene therapy in cancer immunotherapy: why it is no longer just CARs on the road. 2020;9:1588.

[5] Mahoney KM, Rennert PD, Freeman GJJNrDd. Combination cancer immunotherapy and new immunomodulatory targets. 2015;14:561-84.

[6] Kochenderfer JN, Wilson WH, Janik JE, Dudley ME, Stetler-Stevenson M, Feldman SA, et al. Eradication of B-lineage cells and regression of lymphoma in a patient treated with autologous $\mathrm{T}$ cells genetically engineered to recognize CD19. Blood. 2010;116:4099-102.

[7] Mollanoori H, Shahraki H, Rahmati Y, Teimourian S. CRISPR/Cas9 and CAR-T cell, collaboration of two revolutionary technologies in cancer immunotherapy, an instruction for successful cancer treatment. Hum Immunol. 2018;79:876-82.

[8] Lee DW, Kochenderfer JN, Stetler-Stevenson M, Cui YK, Delbrook C, Feldman SA, et al. T cells expressing CD19 chimeric antigen receptors for acute lymphoblastic leukaemia in children and young adults: a phase 1 dose-escalation trial. Lancet. 2015;385:51728.

[9] Brentjens RJ, Davila ML, Riviere I, Park J, Wang X, Cowell LG, et al. CD19-targeted T cells rapidly induce molecular remissions in adults with chemotherapy-refractory acute lymphoblastic leukemia. Sci Transl Med. 2013;5:177ra38. 
[10] Ishizaki Y, Yukaya N, Kusuhara K, Kira R, Torisu H, Ihara K, et al. PD1 as a common candidate susceptibility gene of subacute sclerosing panencephalitis. Human genetics. 2010;127:411-9.

[11] Chevolet I, Speeckaert R, Schreuer M, Neyns B, Krysko O, Bachert C, et al. Characterization of the in vivo immune network of IDO, tryptophan metabolism, PD-L1, and CTLA-4 in circulating immune cells in melanoma. Oncoimmunology. 2015;4:e982382.

[12] Mali P, Yang L, Esvelt KM, Aach J, Guell M, DiCarlo JE, et al. RNA-guided human genome engineering via Cas9. Science (New York, NY). 2013;339:823-6.

[13] Cong L, Ran FA, Cox D, Lin S, Barretto R, Habib N, et al. Multiplex genome engineering using CRISPR/Cas systems. Science (New York, NY). 2013;339:819-23.

[14] Salsman J, Dellaire G. Precision genome editing in the CRISPR era. Biochem Cell Biol. 2017;95:187-201.

[15] Smith-Garvin JE, Koretzky GA, Jordan MS. T cell activation. Annual review of immunology. 2009;27:591-619.

[16] Fukunaga A, Miyamoto M, Cho Y, Murakami S, Kawarada Y, Oshikiri T, et al. CD8+ tumor-infiltrating lymphocytes together with CD4+ tumor-infiltrating lymphocytes and dendritic cells improve the prognosis of patients with pancreatic adenocarcinoma. Pancreas. 2004;28:e26-31.

[17] Oshikiri T, Miyamoto M, Shichinohe T, Suzuoki M, Hiraoka K, Nakakubo Y, et al. Prognostic value of intratumoral CD8+ T lymphocyte in extrahepatic bile duct carcinoma as essential immune response. Journal of surgical oncology. 2003;84:224-8.

[18] Cosulich ME, Rubartelli A, Risso A, Cozzolino F, Bargellesi AJPotNAoS. Functional characterization of an antigen involved in an early step of T-cell activation. 1987;84:4205-9.

[19] Lamers CH, Klaver Y, Gratama JW, Sleijfer S, Debets R. Treatment of metastatic renal cell carcinoma (mRCC) with CAIX CARengineered T-cells-a completed study overview. Biochemical Society transactions. 2016;44:951-9.

[20] Kohn DB, Dotti G, Brentjens R, Savoldo B, Jensen M, Cooper LJ, et al. CARs on track in the clinic. Molecular therapy : the journal of the American Society of Gene Therapy. 2011;19:432-8.

[21] Morgan RA, Yang JC, Kitano M, Dudley ME, Laurencot CM, Rosenberg SA. Case report of a serious adverse event following the administration of $\mathrm{T}$ cells transduced with a chimeric antigen receptor recognizing ERBB2. Molecular therapy : the journal of the American Society of Gene Therapy. 2010;18:843-51.

[22] Caruana I, Savoldo B, Hoyos V, Weber G, Liu H, Kim ES, et al. Heparanase promotes tumor infiltration and antitumor activity of CAR-redirected T lymphocytes. Nature medicine. 2015;21:524-9.

[23] Wilkie S, van Schalkwyk MC, Hobbs S, Davies DM, van der Stegen SJ, Pereira AC, et al. Dual targeting of ErbB2 and MUC1 in breast cancer using chimeric antigen receptors engineered to provide complementary signaling. Journal of clinical immunology. 2012;32:1059-70.

[24] Grada Z, Hegde M, Byrd T, Shaffer DR, Ghazi A, Brawley VS, et al. TanCAR: A Novel Bispecific Chimeric Antigen Receptor for Cancer Immunotherapy. Molecular therapy Nucleic acids. 2013;2:e105.

[25] Thomas R, Al-Khadairi G, Roelands J, Hendrickx W, Dermime S, Bedognetti D, et al. NY-ESO-1 Based Immunotherapy of Cancer: Current Perspectives. Frontiers in immunology. 2018;9:947.

[26] Dominick LA, Denise LC, Daniel H, Elizabeth KB, John BL, Gregory EH, et al. Chapter 23 - Clinical Application of Plasmid-Based Cancer Vaccines. 2014:335-43.

[27] Oka Y, Tsuboi A, Elisseeva OA, Udaka K, Sugiyama H. WT1 as a novel target antigen for cancer immunotherapy. Current cancer drug targets. 2002;2:45-54.

[28] Kita K, Nakase K, Miwa H, Masuya M, Nishii K, Morita N, et al. Phenotypical characteristics of acute myelocytic leukemia associated with the $\mathrm{t}(8 ; 21)(\mathrm{q} 22 ; \mathrm{q} 22)$ chromosomal abnormality: frequent expression of immature B-cell antigen CD19 together with stem cell antigen CD34. Blood. 1992;80:470-7.

[29] Robbins PF, Kawakami Y. Human tumor antigens recognized by T cells. Current opinion in immunology. 1996;8:628-36.

[30] Hegedūs C, Kovács K, Polgár Z, Regdon Z, Szabó É, Robaszkiewicz A, et al. Redox control of cancer cell destruction. Redox biology. 2018;16:59-74.

[31] Cho Y, Miyamoto M, Kato K, Fukunaga A, Shichinohe T, Kawarada Y, et al. CD4+ and CD8+ T cells cooperate to improve prognosis of patients with esophageal squamous cell carcinoma. Cancer research. 2003;63:1555-9.

[32] Schultze JL, Michalak S, Seamon MJ, Dranoff G, Jung K, Daley J, et al. CD40-activated human B cells: an alternative source of highly efficient antigen presenting cells to generate autologous antigen-specific $\mathrm{T}$ cells for adoptive immunotherapy. The Journal of clinical investigation. 1997;100:2757-65.

[33] von Bergwelt-Baildon M, Shimabukuro-Vornhagen A, Popov A, Klein-Gonzalez N, Fiore F, Debey S, et al. CD40-activated B cells express full lymph node homing triad and induce T-cell chemotaxis: potential as cellular adjuvants. Blood. 2006;107:2786-9.

[34] Su KY, Watanabe A, Yeh CH, Kelsoe G, Kuraoka M. Efficient Culture of Human Naive and Memory B Cells for Use as APCs. Journal of immunology (Baltimore, Md : 1950). 2016;197:4163-76.

[35] Boon T, Cerottini JC, Van den Eynde B, van der Bruggen P, Van Pel A. Tumor antigens recognized by T lymphocytes. Annual review of immunology. 1994;12:337-65.

[36] Southam CM, Brunschwig A, Levin AG, Dizon QS. Effect of leukocytes on transplantability of human cancer. Cancer. 1966;19:1743-53.

[37] Cao Y, Trillo-Tinoco J, Sierra RA, Anadon C, Dai W, Mohamed E, et al. ER stress-induced mediator C/EBP homologous protein thwarts effector T cell activity in tumors through T-bet repression. Nature communications. 2019;10:1280.

[38] Meydan İ, Kizil G, Demir H, Toptanci BC, Kizil MJAiTM. In vitro DNA damage, protein oxidation protective activity and antioxidant potentials of almond fruit (Amygdalus trichamygdalus) parts (hull and drupe) using soxhlet ethanol extraction. Advances in Traditional Medicine 2020;20:571-9.

[39] Chen DS, Mellman I. Oncology meets immunology: the cancer-immunity cycle. Immunity. 2013;39:1-10. 
[40] Nagarsheth N, Wicha MS, Zou W. Chemokines in the cancer microenvironment and their relevance in cancer immunotherapy. Nature reviews Immunology. 2017;17:559-72.

[41] Araki K, Morita M, Bederman AG, Konieczny BT, Kissick HT, Sonenberg N, et al. Translation is actively regulated during the differentiation of CD8(+) effector T cells. Nature immunology. 2017;18:1046-57.

[42] Wherry EJ. T cell exhaustion. Nature immunology. 2011;12:492-9.

[43] Hong WX, Haebe S, Lee AS, Westphalen CB, Norton JA, Jiang W, et al. Intratumoral Immunotherapy for Early-stage Solid Tumors. Clinical cancer research : an official journal of the American Association for Cancer Research. 2020;26:3091-9.

[44] Met Ö, Jensen KM, Chamberlain CA, Donia M, Svane IM. Principles of adoptive T cell therapy in cancer. Seminars in immunopathology. 2019;41:49-58.

[45] Vonderheide RH, June CH. Engineering T cells for cancer: our synthetic future. Immunological reviews. 2014;257:7-13.

[46] Andersen R, Donia M, Westergaard MC, Pedersen M, Hansen M, Svane IM. Tumor infiltrating lymphocyte therapy for ovarian cancer and renal cell carcinoma. Human vaccines \& immunotherapeutics. 2015;11:2790-5.

[47] Ping Y, Liu C, Zhang Y. T-cell receptor-engineered T cells for cancer treatment: current status and future directions. Protein \& cell. 2018;9:254-66.

[48] Fesnak AD, June $\mathrm{CH}$, Levine BL. Engineered T cells: the promise and challenges of cancer immunotherapy. Nature reviews Cancer. 2016;16:566-81.

[49] Rezvani K. Adoptive cell therapy using engineered natural killer cells. Bone marrow transplantation. 2019;54:785-8.

[50] Hu W, Wang G, Huang D, Sui M, Xu Y. Cancer Immunotherapy Based on Natural Killer Cells: Current Progress and New Opportunities. Frontiers in immunology. 2019;10:1205.

[51] Miliotou AN, Papadopoulou LC. CAR T-cell Therapy: A New Era in Cancer Immunotherapy. Current pharmaceutical biotechnology. 2018;19:5-18.

[52] Feins S, Kong W, Williams EF, Milone MC, Fraietta JA. An introduction to chimeric antigen receptor (CAR) T-cell immunotherapy for human cancer. American journal of hematology. 2019;94:S3-s9.

[53] Marin-Acevedo JA, Soyano AE, Dholaria B, Knutson KL, Lou Y. Cancer immunotherapy beyond immune checkpoint inhibitors. Journal of hematology \& oncology. 2018;11:8.

[54] Pardoll DM. The blockade of immune checkpoints in cancer immunotherapy. Nature reviews Cancer. 2012;12:252-64.

[55] Sasidharan Nair V, Elkord E. Immune checkpoint inhibitors in cancer therapy: a focus on T-regulatory cells. Immunology and cell biology. 2018;96:21-33.

[56] Jiang Y, Chen M, Nie H, Yuan Y. PD-1 and PD-L1 in cancer immunotherapy: clinical implications and future considerations. Human vaccines \& immunotherapeutics. 2019;15:1111-22.

[57] Alsaab HO, Sau S, Alzhrani R, Tatiparti K, Bhise K, Kashaw SK, et al. PD-1 and PD-L1 Checkpoint Signaling Inhibition for Cancer Immunotherapy: Mechanism, Combinations, and Clinical Outcome. Frontiers in pharmacology. 2017;8:561.

[58] Weiss JM, Subleski JJ, Wigginton JM, Wiltrout RH. Immunotherapy of cancer by IL-12-based cytokine combinations. Expert opinion on biological therapy. 2007;7:1705-21.

[59] Waldmann TA. Cytokines in Cancer Immunotherapy. Cold Spring Harbor perspectives in biology. $2018 ; 10$.

[60] Dranoff G. Cytokines in cancer pathogenesis and cancer therapy. Nature reviews Cancer. 2004;4:11-22.

[61] Berraondo P, Sanmamed MF, Ochoa MC, Etxeberria I, Aznar MA, Pérez-Gracia JL, et al. Cytokines in clinical cancer immunotherapy. British journal of cancer. 2019;120:6-15.

[62] Scott AM, Wolchok JD, Old LJ. Antibody therapy of cancer. Nature reviews Cancer. 2012;12:278-87.

[63] Hafeez U, Gan HK, Scott AM. Monoclonal antibodies as immunomodulatory therapy against cancer and autoimmune diseases. Current opinion in pharmacology. 2018;41:114-21.

[64] Adams GP, Weiner LM. Monoclonal antibody therapy of cancer. Nature biotechnology. 2005;23:1147-57.

[65] Krishnamurthy A, Jimeno AJP, therapeutics. Bispecific antibodies for cancer therapy: A review. 2018;185:122-34.

[66] Runcie K, Budman DR, John V, Seetharamu NJMM. Bi-specific and tri-specific antibodies-the next big thing in solid tumor therapeutics. 2018;24:1-15.

[67] Dreier T, Lorenczewski G, Brandl C, Hoffmann P, Syring U, Hanakam F, et al. Extremely potent, rapid and costimulation-independent cytotoxic T-cell response against lymphoma cells catalyzed by a single-chain bispecific antibody. International journal of cancer. 2002;100:690-7.

[68] Brischwein K, Parr L, Pflanz S, Volkland J, Lumsden J, Klinger M, et al. Strictly target cell-dependent activation of T cells by bispecific single-chain antibody constructs of the BiTE class. Journal of immunotherapy (Hagerstown, Md : 1997). 2007;30:798807.

[69] Roumenina LT, Daugan MV, Petitprez F, Sautès-Fridman C, Fridman WH. Context-dependent roles of complement in cancer. Nature reviews Cancer. 2019;19:698-715.

[70] Baeuerle PA, Kufer P, Bargou R. BiTE: Teaching antibodies to engage T-cells for cancer therapy. Current opinion in molecular therapeutics. 2009;11:22-30.

[71] Bargou R, Leo E, Zugmaier G, Klinger M, Goebeler M, Knop S, et al. Tumor regression in cancer patients by very low doses of a T cell-engaging antibody. Science (New York, NY). 2008;321:974-7.

[72] Hoffman LM, Gore L. Blinatumomab, a Bi-Specific Anti-CD19/CD3 BiTE(®) Antibody for the Treatment of Acute Lymphoblastic Leukemia: Perspectives and Current Pediatric Applications. Frontiers in oncology. 2014;4:63.

[73] Brischwein K, Schlereth B, Guller B, Steiger C, Wolf A, Lutterbuese R, et al. MT110: a novel bispecific single-chain antibody construct with high efficacy in eradicating established tumors. Molecular immunology. 2006;43:1129-43. 
[74] Maetzel D, Denzel S, Mack B, Canis M, Went P, Benk M, et al. Nuclear signalling by tumour-associated antigen EpCAM. Nature cell biology. 2009;11:162-71.

[75] Ran FA, Cong L, Yan WX, Scott DA, Gootenberg JS, Kriz AJ, et al. In vivo genome editing using Staphylococcus aureus Cas9. Nature. 2015;520:186-91.

[76] Swiech L, Heidenreich M, Banerjee A, Habib N, Li Y, Trombetta J, et al. In vivo interrogation of gene function in the mammalian brain using CRISPR-Cas9. Nature biotechnology. 2015;33:102-6.

[77] Jain KK. Personalized cancer vaccines. Expert opinion on biological therapy. 2010;10:1637-47.

[78] Oyadomari S, Mori M. Roles of CHOP/GADD153 in endoplasmic reticulum stress. Cell death and differentiation. 2004;11:381-9.

[79] Kopito RR. Aggresomes, inclusion bodies and protein aggregation. Trends in cell biology. 2000;10:524-30.

[80] Kaufman RJ. Stress signaling from the lumen of the endoplasmic reticulum: coordination of gene transcriptional and translational controls. Genes \& development. 1999;13:1211-33.

[81] Mori K. Tripartite management of unfolded proteins in the endoplasmic reticulum. Cell. 2000;101:451-4.

[82] Ron D. Translational control in the endoplasmic reticulum stress response. The Journal of clinical investigation. 2002;110:1383-8.

[83] Kaufman RJ. Orchestrating the unfolded protein response in health and disease. The Journal of clinical investigation. 2002;110:1389-98.

[84] Harding HP, Calfon M, Urano F, Novoa I, Ron D. Transcriptional and translational control in the Mammalian unfolded protein response. Annual review of cell and developmental biology. 2002;18:575-99.

[85] Pauken KE, Wherry EJJTii. Overcoming T cell exhaustion in infection and cancer. 2015;36:265-76.

[86] Wang JC, Xu Y, Huang ZM, Lu XJJJocb. T cell exhaustion in cancer: mechanisms and clinical implications. 2018;119:4279-86.

[87] Barber DL, Wherry EJ, Masopust D, Zhu B, Allison JP, Sharpe AH, et al. Restoring function in exhausted CD8 T cells during chronic viral infection. Nature. 2006;439:682-7.

[88] Yong CSM, Dardalhon V, Devaud C, Taylor N, Darcy PK, Kershaw MH. CAR T-cell therapy of solid tumors. Immunology and cell biology. 2017;95:356-63.

[89] Schumann K, Lin S, Boyer E, Simeonov DR, Subramaniam M, Gate RE, et al. Generation of knock-in primary human T cells using Cas9 ribonucleoproteins. Proceedings of the National Academy of Sciences of the United States of America. 2015;112:10437-42.

[90] Wherry EJ, Kurachi M. Molecular and cellular insights into T cell exhaustion. Nature reviews Immunology. 2015;15:486-99.

[91] Gao Q, Dong X, Xu Q, Zhu L, Wang F, Hou Y, et al. Therapeutic potential of CRISPR/Cas9 gene editing in engineered T-cell therapy. 2019;8:4254-64.

[92] Willemsen RA, Debets R, Hart E, Hoogenboom HR, Bolhuis RL, Chames P. A phage display selected fab fragment with MHC class I-restricted specificity for MAGE-A1 allows for retargeting of primary human T lymphocytes. Gene therapy. 2001;8:16018.

[93] Maus MV, Grupp SA, Porter DL, June CH. Antibody-modified T cells: CARs take the front seat for hematologic malignancies. Blood. 2014;123:2625-35.

[94] Wu H-y, Cao C-yJBifg. The application of CRISPR-Cas9 genome editing tool in cancer immunotherapy. 2019;18:129-32.

[95] Piganeau M, Ghezraoui H, De Cian A, Guittat L, Tomishima M, Perrouault L, et al. Cancer translocations in human cells induced by zinc finger and TALE nucleases. 2013;23:1182-93.

[96] Provasi E, Genovese P, Lombardo A, Magnani Z, Liu P-Q, Reik A, et al. Editing T cell specificity towards leukemia by zinc finger nucleases and lentiviral gene transfer. 2012;18:807-15.

[97] Deltcheva E, Chylinski K, Sharma CM, Gonzales K, Chao Y, Pirzada ZA, et al. CRISPR RNA maturation by trans-encoded small RNA and host factor RNase III. Nature. 2011;471:602-7.

[98] Jinek M, Chylinski K, Fonfara I, Hauer M, Doudna JA, Charpentier E. A programmable dual-RNA-guided DNA endonuclease in adaptive bacterial immunity. Science (New York, NY). 2012;337:816-21.

[99] Cheng AW, Wang H, Yang H, Shi L, Katz Y, Theunissen TW, et al. Multiplexed activation of endogenous genes by CRISPR-on, an RNA-guided transcriptional activator system. Cell research. 2013;23:1163-71.

[100] DiCarlo JE, Norville JE, Mali P, Rios X, Aach J, Church GM. Genome engineering in Saccharomyces cerevisiae using CRISPRCas systems. Nucleic acids research. 2013;41:4336-43.

[101] Hwang WY, Fu Y, Reyon D, Maeder ML, Tsai SQ, Sander JD, et al. Efficient genome editing in zebrafish using a CRISPR-Cas system. Nature biotechnology. 2013;31:227-9.

[102] Hilton IB, D'Ippolito AM, Vockley CM, Thakore PI, Crawford GE, Reddy TE, et al. Epigenome editing by a CRISPR-Cas9-based acetyltransferase activates genes from promoters and enhancers. Nature biotechnology. 2015;33:510-7.

[103] Kearns NA, Pham H, Tabak B, Genga RM, Silverstein NJ, Garber M, et al. Functional annotation of native enhancers with a Cas9-histone demethylase fusion. Nature methods. 2015;12:401-3.

[104] Ran FA, Hsu PD, Lin CY, Gootenberg JS, Konermann S, Trevino AE, et al. Double nicking by RNA-guided CRISPR Cas9 for enhanced genome editing specificity. Cell. 2013;154:1380-9.

[105] Kim S, Kim D, Cho SW, Kim J, Kim JS. Highly efficient RNA-guided genome editing in human cells via delivery of purified Cas9 ribonucleoproteins. Genome research. 2014;24:1012-9.

[106] Wang W, Ye C, Liu J, Zhang D, Kimata JT, Zhou P. CCR5 gene disruption via lentiviral vectors expressing Cas9 and single guided RNA renders cells resistant to HIV-1 infection. PloS one. 2014;9:e115987.

[107] Li JF, Norville JE, Aach J, McCormack M, Zhang D, Bush J, et al. Multiplex and homologous recombination-mediated genome editing in Arabidopsis and Nicotiana benthamiana using guide RNA and Cas9. Nature biotechnology. 2013;31:688-91.

[108] Chi S, Weiss A, Wang H. A CRISPR-Based Toolbox for Studying T Cell Signal Transduction. BioMed research international. 2016;2016:5052369. 
[109] Hendel A, Bak RO, Clark JT, Kennedy AB, Ryan DE, Roy S, et al. Chemically modified guide RNAs enhance CRISPR-Cas genome editing in human primary cells. Nature biotechnology. 2015;33:985-9.

[110] Ren J, Liu X, Fang C, Jiang S, June CH, Zhao Y. Multiplex Genome Editing to Generate Universal CAR T Cells Resistant to PD1 Inhibition. Clinical cancer research : an official journal of the American Association for Cancer Research. 2017;23:2255-66.

[111] Li Y, Kurlander RJJJotm. Comparison of anti-CD3 and anti-CD28-coated beads with soluble anti-CD3 for expanding human T cells: differing impact on CD8 T cell phenotype and responsiveness to restimulation. 2010;8:1-15.

[112] Liu X, Zhang Y, Cheng C, Cheng AW, Zhang X, Li N, et al. CRISPR-Cas9-mediated multiplex gene editing in CAR-T cells. Cell research. 2017;27:154-7.

[113] Ren J, Zhang X, Liu X, Fang C, Jiang S, June CH, et al. A versatile system for rapid multiplex genome-edited CAR T cell generation. Oncotarget. 2017;8:17002-11. 